\title{
Produção tecnológica da Universidade Estadual de Londrina (UEL): mapeamento da área de Ciências Agrárias pela Plataforma Lattes
}

\author{
Natan Tiago Batista Serzedello', Maria Inês Tomaél²
}

\begin{abstract}
Resumo
Introdução: Os produtos e os processos tecnológicos empregados com o fim de solucionar os problemas práticos da sociedade compreendem a produção tecnológica. Esta se constitui como o meio essencial de mensuração do desenvolvimento tecnológico do ambiente em que a instituição está inserida. 0 objetivo desta pesquisa foi averiguar a produção tecnológica da área de Ciências Agrárias na Universidade Estadual de Londrina (UEL). Método: Identificação e análise da produção tecnológica, por meio dos currículos, disponíveis na Plataforma Lattes, de 51 professores que receberam bolsas do Programa de Iniciação Científica (PROIC) da UEL. Os dados coletados para a análise foram tabulados e categorizados por tipologias de produções tecnológicas. Resultados: Dos 65 itens cadastrados nos currículos Lattes dos professores referem-se à produção tecnológica, a qual foi mapeada, descrevendo-se as tipologias identificadas. Observouse que as especialidades mais inovadoras são pertinentes a Agronomia; Recursos Florestais e Engenharia Florestal; Engenharia Agrícola; Zootecnia; Medicina Veterinária; Recursos Pesqueiros e Engenharia de Pesca; Ciência e Tecnologia de Alimentos. Conclusões: Verificou-se que a produção tecnológica encontrada, decorrente de atividades de pesquisas de desenvolvimento tecnológico, foi disseminada por meio da produção bibliográfica, principalmente por artigos de periódicos. Os pesquisadores participantes deste estudo fazem parcerias em um mesmo Departamento, ou em Departamentos variados, dentro e fora da Universidade, interagindo e compartilhando as experiências, o conhecimento e os equipamentos, o que potencializa uma produção tecnológica mais bem formulada e com maiores chances de êxito. Um percentual considerável de artigos foi publicado em periódicos adeptos da filosofia da Open Archives Initiative (OAI), o que possibilita o acesso livre e favorece a disseminação dos resultados das pesquisas.
\end{abstract}

\section{Palavras-chave}

Produção tecnológica; Desenvolvimento tecnológico; Inovação tecnológica.

\section{Introdução}

A produção tecnológica é caracterizada, por uma comunidade científica, pela geração de produtos e de processos tecnológicos, com o intuito de contribuir na solução de problemas práticos. A produção tecnológica geralmente tem a finalidade de atender as necessidades da sociedade, por meio da criação de invenções e, por consequência, impacta o desenvolvimento tecnológico, econômico e social.

O espaço tecnológico, ou ambiente de produção tecnológica, parte do conjunto da ciência, da tecnologia e da informação. Esse ambiente é assim denominado porque emprega a tecnologia para a geração da produção tecnológica. Como exemplos dessa produção, podem-se citar as patentes, os manuais, as metodologias, os processos tecnológicos e de produção e os relatórios de pesquisas.

Os ambientes de produção tecnológica são configurados no Brasil, principalmente, pelas Universidades, parques tecnológicos, institutos tecnológicos e de pesquisa, os quais possuem a infra-estrutura espacial para desenvolver pesquisa aplicada.

As pesquisas aplicadas desenvolvidas nesses ambientes, normalmente, são fundamentadas pelo conhecimento científico, resultante de pesquisa 
básica, que tem origem nas Universidades e estas resultam em produtos e processos denominados produção tecnológica.

O desenvolvimento social pode ser verificado por meio de indicadores estatísticos de produção tecnológica, que expõem o potencial qualitativo e quantitativo do progresso das Universidades, institutos tecnológicos e de pesquisa. Esse progresso está associado à criação de invenções, inovações de sucesso e quantidade de patentes. Quando essas instituições de pesquisa não apresentam alterações inovativas bem sucedidas (produções tecnológicas baseadas em inovações já existentes) são consideradas improdutivas e isso compromete a capacidade de obtenção de recursos.

Pela literatura, verifica-se que o indicador de produção tecnológica mais empregado é o número de patentes. Segundo Bernardes (2003, p. 152), "as patentes formam até hoje o principal indicador de produção tecnológica nos países centrais e o número delas é uma medida que auxilia a avaliação da capacidade de inovação". Desde o final da década de 1990, vem-se aplicando e melhorando a eficiência e eficácia desse indicador focando somente nas patentes.

Os dados disponíveis sobre produção tecnológica são compilados por meio da elaboração de estatísticas dos produtos e processos tecnológicos, e estes auxiliam no desenvolvimento de pesquisas e no aprimoramento de artefatos tecnológicos, que refletem no setor produtivo e na qualidade de vida das pessoas.

Depois de tornarem-se públicas, as estatísticas de produção tecnológica servem de incentivo ao progresso, ao reconhecimento ou são utilizadas como base para novos estudos, formando o processo de inovação.

Além das patentes, outras formas de produção tecnológica também são de relevância para o desenvolvimento econômico, social, cultural, político e organizacional, como: manuais, metodologias, processos desenvolvidos e a participação em feiras e exposições. Essas formas de produção foram foco desta pesquisa na área de Ciências Agrárias da Universidade Estadual de Londrina (UEL). As diferentes formas de produção tecnológica agregam conhecimentos para a área em que são produzidas; contudo, apenas as patentes aparecem na literatura como indicadores de produção tecnológica, para averiguação da evolução tecnológica.

O tema produção tecnológica é pouco explorado pela literatura. A identificação de artefatos tecnológicos na UEL, na área de Ciências Agrárias, pode garantir o acesso a informações com potencial de oportunidades mercadológicas, como também a visão do montante da variedade de invenções e a abertura a novos conhecimentos, por meio das inovações produzidas na Universidade.

A pesquisa foi realizada na área de Ciências Agrárias com o objetivo de prospectar a produção tecnológica da Universidade Estadual de Londrina (UEL). Os objetivos específicos da pesquisa foram: mapear as formas de produção tecnológica; descrever as tipologias de produção tecnológica; e identificar os canais de comunicação mais utilizados.

\section{Desenvolvimento tecnológico}

Quando a sociedade sente a falta de algo necessário para o seu auxílio, progresso e melhoria surgem as invenções, que podem gerar produtos e processos com o propósito de sanarem as necessidades do meio em que estão inseridos. Schumpeter (1996, p. 11) define invenção como "processo de criação de novos produtos ou métodos técnicos direcionados para o meio econômico moldado por lógicas específicas." Ou seja, a necessidade de satisfação serve de incentivo para o surgimento das invenções.

Pensando em maior conforto, comodidade e melhores condições de vida, os integrantes da sociedade sempre geram produtos, processos e instrumentos técnicos, vinculados em sua maioria à tecnologia. 
Os artefatos de base tecnológica são denominados produtos ou processos tecnológicos, isto por possuírem informações tecnológicas embutidas, que geralmente são elaboradas para sanar os problemas práticos da sociedade.

\section{Tecnologia}

Seguindo uma tendência evolucionista, vários autores mencionam que a tecnologia teve seu início quando o homem começou a usar as mãos para capturar seu alimento e a construir itens para melhorias no seu cotidiano, tais como as técnicas e as ferramentas por eles utilizadas.

A evolução do homem, até alcançar sua forma atual, permitiu seu progresso gradual, causando uma evolução também nas técnicas, à medida que o cérebro evoluía. Com o uso do cérebro, sobreveio a organização social e o homem se distanciou do mundo animal.

De acordo com Goldemberg (1978, p. 157), tecnologia é "o conjunto de conhecimentos de que uma sociedade dispõe sobre ciências e artes industriais, incluindo os fenômenos sociais e físicos, e a aplicação destes princípios à produção de bens e serviços". A tecnologia agrega valor também aos fatores técnicos, políticos, econômicos e sociais.

A concepção convencional da tecnologia é a de geração de produtos e processos de ciência aplicada, ou seja, resulta em itens tecnológicos. Nada mais é que a junção da teoria e prática, o saber e o fazer. A seleção das tecnologias é compreendida pela busca em conjuntos de tecnologias ou a procura por produtos e processos com tecnologias, que são denominados produção tecnológica.

\section{Produção tecnológica}

O conceito de produção tecnológica foi inicialmente disseminado por sociólogos que criaram teorias que mencionavam produtos $\mathrm{e}$ processos tecnológicos gerados por inspirações, sem embasamento ou acúmulo de conhecimento. A literatura (OGBUM, THOMAS, 1922; GILFILAN, 1935 apud CONCEIÇÃO, 2003), ressalta que sociólogos da Universidade de Chicago acreditavam que as invenções eram quase um milagre, nascidas por meio da intuição.

É necessário ter uma noção preliminar, ou uma base inicial - adquirida a partir de um conhecimento já existente - para se criar uma invenção. Marx confirma esta assertiva em suas teorias, quando menciona a necessidade de conhecimento prévio e de acúmulo de conhecimento para desenvolver os produtos e processos tecnológicos. Os sociólogos (OGBUM, THOMAS, 1922; GILFILAN, 1935 apud CONCEIÇÃO, 2003), fundamentados pela ótica marxista, ressaltam o fato de que os países menos desprovidos de desenvolvimento necessitam seguir os passos dos países industrializados para atingirem a sua evolução (MACHADO, 2006).

A identificação da produção e o crescimento dos produtos e processos tecnológicos nos países ocidentais surgiram no século XVIII, e com isso, também a demanda de produção tecnológica. $\mathrm{O}$ conjunto de produtos e processos tecnológicos compõe a produção tecnológica, a qual visa à

Quadro 1 - Tipos de produção tecnológica

\begin{tabular}{|l|l|}
\hline \multicolumn{2}{|c|}{ Tipos de produção tecnológica } \\
\hline Modalidades & \multicolumn{1}{c|}{ Especificação } \\
\hline Softwares & Abrange os sistemas computacionais. \\
\hline Produtos & Projetos, protótipos, pilotos entre outros. \\
\hline Processos & $\begin{array}{l}\text { Processo ou técnica com fins tecnológicos } \\
\text { aplicáveis. }\end{array}$ \\
\hline $\begin{array}{l}\text { Cartas mapas } \\
\text { ou similares }\end{array}$ & $\begin{array}{l}\text { Produtos cartográficos desenvolvidos } \\
\text { para tecnológicos aplicáveis. }\end{array}$ \\
\hline $\begin{array}{l}\text { Relatório de } \\
\text { pesquisa }\end{array}$ & $\begin{array}{l}\text { Relatórios periódicos ou finais que } \\
\text { descrevem as pesquisas que contenham } \\
\text { fins tecnológicos. }\end{array}$ \\
\hline Patente & $\begin{array}{l}\text { Fonte de informação tecnológica. } \\
\text { Criações, invenções no âmbito da } \\
\text { tecnologia. }\end{array}$ \\
\hline Manuais & $\begin{array}{l}\text { Manuais que documentem e descrevam o } \\
\text { produto. }\end{array}$ \\
\hline Fonte: Baseado na Plataforma Lattes ${ }^{1}$ - CNPO.
\end{tabular}

${ }^{1}$ http://plsql1.cnpq.br/images/ajuda/index.html. 
solução dos problemas e o desenvolvimento tecnológico da sociedade.

A vasta produção de invenções e inovações constantes, de acordo com Schumpeter (1996), é classificada como idéia original que traz reflexos de ordem econômica, social e cultural. Há uma grande variabilidade das formas de produção tecnológica e as suas diversas classificações, como as exemplificadas no Quadro 1.

Essas tipologias (Quadro 1) são decorrentes de pesquisas de desenvolvimento tecnológico e representam ou descrevem inovações. Os tipos de produção apresentados são consolidados, visto que figuram na Plataforma Lattes do Conselho Nacional de Desenvolvimento Científico e Tecnológico (CNPq).

\section{Inovação}

A inovação acontece quando o conhecimento gerado pela pesquisa básica se torna aplicado, possibilitando a criação de produtos e processos, seu incremento ou aperfeiçoamento, ou seja, quando esta agrega benefícios a uma tecnologia existente, gerando uma nova. Joseph Schumpeter foi o primeiro a relacionar a inovação ao desenvolvimento econômico, pois acreditava no processo de criação fundamentado no conhecimento acumulado, ligado ao processo de desenvolvimento econômico.

Para Lemos (1999, p. 126) inovaçãoé um "processo pelo qual produtores dominam e implementam o projeto e produção de bens e serviços que são novos para os mesmos, a despeito de serem ou não novos para seus concorrentes - domésticos ou estrangeiros". Esse conceito é complementado por Caldas e colaboradores (2001, p. 2) quando dizem que o conceito de inovação "ainda não está completamente internalizado nas nossas instituições, e serão necessários muitos esforços até que se tenha no Brasil um sistema nacional de inovação forte e consolidado”.

\section{Inovação tecnológica nas universidades}

Por meio da pesquisa de caráter inovador, ocorre o desenvolvimento que abre oportunidades a serem apropriadas pela sociedade.

No Brasil, por meio da pesquisa nas Universidades, surgem produtos e processos tecnológicos inovadores, que podem contribuir para sanar as necessidades da sociedade. De acordo com Fava-de-Moraes (2000, p. 9), “a pesquisa básica executada 'espontaneamente' pela Universidade ainda é comprovadamente a maior fonte de resultados aplicáveis do que a pesquisa dita 'encomendada' por empresa." E corrobora com a pesquisa aplicada e com processos de inovação tecnológica nas Universidades, o que possibilita a formação de alunos empreendedores, que são capacitados a inovar fora do meio acadêmico.

De Acordo com Fava-de-Moraes (2000, p. 1):

O papel da universidade é inquestionável para a formação de pessoas qualificadas e para o desenvolvimento socioeconômico de um país, principalmente quando fundamentado em uma política científica-tecnológica articulada no espaço das relações entre universidade, Estado, empresariado e outros setores sociais.

O processo de produção do conhecimento na inovação tecnológica é formado pelo ciclo de idéias no âmbito da ciência, por meio de pesquisa, criatividade e experimentação, obtendo um produto ou processo de fator aplicável. Este processo de desenvolvimento científico e tecnológico aprimora o bem-estar da sociedade e a tecnologia acarreta a evolução da população, devendo estes ser conduzidos em conjunto.

O desenvolvimento de inovação tecnológica em Universidades, no Brasil, ainda é muito baixo e necessita expansão para atender as necessidades da sociedade com tecnologias adequadas, produtos, processos e serviços que promovam o crescimento econômico e social.

Para isso é necessária a interação da comunidade científica acadêmica com o setor privado, visto 
que muitas vezes a inovação tecnológica inicia-se nas Universidades, mas não se concretiza.

O que acontece nas Universidades é a dominação do formal, a forma de como se executa, não havendo o questionamento sobre as finalidades dos produtos ou processos elaborados. Enfim, não se disseminam informações que poderiam, muitas vezes, ser úteis à sociedade ou também servir de apoio a outras invenções. Caldas e colaboradores $(2001$, p. 2$)$ consideram que:

O momento é o mais propício para que o País perceba que o único caminho a ser trilhado por países em desenvolvimento em busca de suas chances de competir e sobreviver no mundo do futuro deve apropriar-se dos resultados da ciência e utilizá-los em benefício da sociedade, ou seja, promover e estabelecer o processo de inovação.

Para tanto, o ato de explorar toda forma de inovação tecnológica nas comunidades científicoacadêmicas é fundamental para que aconteça o desenvolvimento econômico, social e político da sociedade, gerando bem-estar e avanço tecnológico. Fava-de-Moraes (2000, p. 11) afirma que:

O Brasil não deve se iludir com importantes conquistas eventualmente exploradas com personalismo e ufania na mídia. O Brasil precisa conhecer o quadro real para ousar com humildade e exigir que decisões de política científicotecnológica sejam tomadas conjuntamente pelas Universidades-Governo-Setor privado (triângulo de Sábato ou tríplice hélice).

É muito importante disseminar resultados de estudos científicos, mesmo daquelas que não obtiveram sucesso, para que ocorram mudanças futuras. Esta ação possibilitará que as informações resultantes de pesquisas possam fazer a diferença. Embora seus efeitos não sejam perceptíveis no curto prazo, tais informações poderão ser utilizadas em longo prazo, se estiverem disponíveis.

\section{Procedimentos metodológicos}

A pesquisa foi realizada na área de Ciências Agrárias da UEL, por apresentar um grande índice de professores bolsistas de produtividade em pesquisa do $\mathrm{CNPq}$ - comparada a outros setores da UEL.

Situada na cidade de Londrina (Paraná), a UEL é a maior universidade do Estado do Paraná e apresenta índices anuais de produtividade crescente. O Centro de Ciências Agrárias (CCA) da UEL possui os cursos de graduação em: Agronomia, Zootecnia e Medicina Veterinária. Contempla também os programas de pós-graduação em: Agronomia (Mestrado e Doutorado), Ciência Animal (Mestrado e Doutorado), Ciência de Alimentos (Mestrado e Doutorado) e diversos cursos de especialização (lato sensu).

O CCA possui 118 professores. Para a definição da amostra, utilizou-se o edital que discrimina os nomes dos professores que receberam bolsas, na UEL, do Programa de Iniciação Científica (PROIC) que distribui bolsas de Iniciação Científica da própria UEL, da Fundação Araucária e do Programa Institucional de Bolsas de Iniciação Científica (PIBIC) do CNPq. Este critério foi empregado por eleger para o recebimento de bolsas os professores/ pesquisadores mais produtivos. Cinquenta e um professores orientadores listados no Edital PROIC na área de Ciências Agrárias da UEL foram os que fizeram parte da nossa pesquisa.

Para a coleta de dados foram desenvolvidos os seguintes procedimentos: a) Identificação do currículo dos professores na Plataforma Lattes; b) Levantamento e análise da produção na seção de Produção em CT\&A do currículo Lattes. Foi feito um exame das produções bibliográficas, produções técnicas e demais trabalhos.

Para a produção bibliográfica, considerou-se:

- Título de cada produção;

- Resumo e leitura técnica do artigo em questão (sempre que disponível na Web). 
Para a produção técnica, considerou-se:

- Título de cada produção;

- Resumo (quando este estava disponível na Web).

Para a categoria de "demais trabalhos" cadastrados no currículo lattes, analisou-se:

- Título de cada produção;

- Resumo (quando este estava disponível na Web).

O instrumento utilizado para a coleta foi um formulário, que possibilitou levantar as informações de identificação dos docentes e dados para o levantamento de sua produção tecnológica. Para cada produção tecnológica encontrada, preencheu-se um formulário.

\section{Produção tecnológica: resultados da pesquisa}

Dentre os 51 currículos de professores pesquisados, 25 não possuem produção tecnológica, porém apresentam produção bibliográfica. Isto corrobora a afirmação de Fujino, Stal e Plonski (1999) de que há a necessidade de aumento progressivo de conhecimento científico para a obtenção do progresso técnico.

Para os outros 26 participantes desta pesquisa, foi identificada produção tecnológica disseminada por meio da literatura científica - cadastrada no currículo lattes no item Produção Bibliográfica, na Produção Técnica, ou nos Demais Trabalhos.

A produção dos professores do CCA da UEL não possui indicador de mensuração relevante que a evidencie, mesmo que esta traga benefícios, modificações, e melhorias à sociedade. Isto se verifica em virtude de nenhum dos currículos analisados incluírem dados sobre a solicitação ou concessão de patentes. Sabe-se que a patente é o principal indicador de produção tecnológica, conforme destaca Bernardes (2003, p. 152), isso confirma que as produções tecnológicas encontradas neste estudo não foram mensuradas e incluídas como parâmetro para o desenvolvimento econômico e tecnológico.

\section{Tipologia e formas de produção tecnológica}

A produção tecnológica encontrada inclui: softwares, produtos, processos e manuais, os quais são classificados como idéias originais, e podem ter reflexos de ordem cultural, social e econômica conforme evidenciado por Schumpeter (1996). O Quadro 2 sintetiza os dados encontrados na pesquisa.

Quadro 2 - Especialidade e produção

\begin{tabular}{|c|c|}
\hline Especialidade & $\begin{array}{l}\text { Tipo de } \\
\text { Produção } \\
\text { Tecnológica }\end{array}$ \\
\hline $\begin{array}{l}\text { Entomologia Agrícola, Defesa Fitossanitária } \\
\text { Microbiologia Agrícola }\end{array}$ & $\begin{array}{l}03 \text { processos } \\
05 \text { produtos }\end{array}$ \\
\hline Manejo e conservação do solo & 03 processos \\
\hline Manejo e Tratos Culturais & 02 produtos \\
\hline Fitopatologia & $\begin{array}{l}06 \text { softwares } \\
04 \text { processos }\end{array}$ \\
\hline Tecnologia de Aplicação & 02 produtos \\
\hline $\begin{array}{l}\text { Instrumentação em máquinas e Implementos } \\
\text { Agrícolas }\end{array}$ & 02 produtos \\
\hline $\begin{array}{l}\text { Agricultura; Produção e Beneficiamento de } \\
\text { Sementes }\end{array}$ & 01 produto \\
\hline Controle populacional de Animais & 01 processo \\
\hline Engenharia de Alimentos & $\begin{array}{l}01 \text { processo } \\
01 \text { software }\end{array}$ \\
\hline $\begin{array}{l}\text { Avaliação e controle da qualidade de alimentos; } \\
\text { Química, física, Físico-química e Bioquímica dos } \\
\text { Alimentos e das Matérias-primas }\end{array}$ & $\begin{array}{l}01 \text { manual } \\
01 \text { processo } \\
02 \text { produtos }\end{array}$ \\
\hline Embalagens de produtos alimentares & 02 produtos \\
\hline Clínica Veterinária; Obstetrícia Animal & 01 processo \\
\hline Doenças parasitárias de animais & 06 produtos \\
\hline Zoonoses e Saúde Pública & $\begin{array}{l}03 \text { manuais } \\
02 \text { produtos } \\
01 \text { processo }\end{array}$ \\
\hline Medicina Veterinária Preventiva & 02 manuais \\
\hline Valor nutritivo de Alimentos & 03 processos \\
\hline Tecnologia de produtos de origem vegetal & $\begin{array}{l}04 \text { processos } \\
02 \text { produtos }\end{array}$ \\
\hline Produção animal em ruminantes & 01 produto \\
\hline Conservação de Alimentos para animais & 01 software \\
\hline $\begin{array}{l}\text { Química, física, Físico-química e Bioquímica dos } \\
\text { Alimentos e das Matérias-primas; Tecnologia de } \\
\text { alimentos dietéticos e Nutricionais }\end{array}$ & $\begin{array}{l}01 \text { software } \\
01 \text { produto }\end{array}$ \\
\hline
\end{tabular}


Observa-se que as especialidades mais inovadoras são pertinentes a: Agronomia; Recursos Florestais e Engenharia Florestal; Engenharia Agrícola; Zootecnia; Medicina Veterinária; Recursos Pesqueiros e Engenharia de Pesca; Ciência e Tecnologia de Alimentos.

Figura 1 - Mapeamento da produção tecnológica na área de Ciências Agrárias da UEL
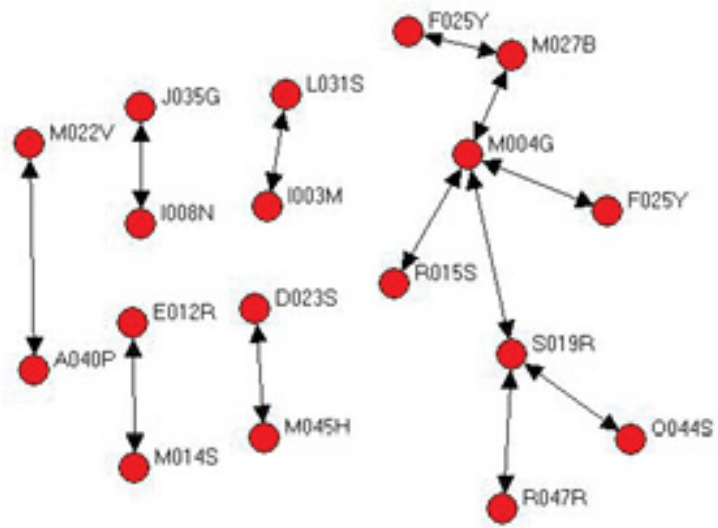

Fonte: os autores.

Na Figura 1, cada círculo contém um código que corresponde a um pesquisador. Pode-se observar que cinco das produções tecnológicas encontradas em coautoria foram produzidas por pelo menos dois atores ${ }^{2}$ participantes desta pesquisa. Os atores com maior índice de trabalhos em coautoria são os que receberam os códigos M004G e S019R. O M004G possui quatro ligações de coautoria, e o S019R sustenta três ligações (coautoria), ambos com diferentes professores.

Dos pesquisadores que tiveram os currículos analisados, os pertencentes ao Departamento de Agronomia foram os que mais produziram, com $43 \%$ do total dos produtos e com $52 \%$ do total de processos encontrados. Esses produtos e processos pertencentes ao Departamento de Agronomia são focados nas temáticas: valores nutritivos de alimentos, engenharia de alimentos, entomologia agrícola, tecnologia de aplicação de máquinas e implementos agrícola, manejo e conservação do solo, e defesa fitossanitária.
Os pesquisadores desse departamento também se destacaram com $67 \%$ do total da produção de softwares desenvolvidos. Estes softwares podem ser classificados nas especialidades de epidemias agrícolas, riscos climáticos e fitopatologia.

O Departamento de Agronomia, devido ao alto número de professores contemplados com bolsa de iniciação científica, apresentou o maior número de produções tecnológicas, e também abrangeu temáticas variadas e diversificados tipos de produções.

Do Departamento de Medicina Veterinária Preventiva, os pesquisadores detiveram 29\% do total de produtos identificados. Os produtos oriundos desse departamento têm o foco nas temáticas: zoonoses e saúde pública; medicina veterinária preventiva; e doenças parasitárias.

Em relação à produção total de manuais, os pesquisadores do Departamento de Medicina Veterinária Preventiva atingiram $83 \%$ da produção, deste total, seis manuais são na temática de Zoonoses e Saúde Pública.

Observa-se que os pesquisadores do Departamento de Ciência e Tecnologia de Alimentos foram os únicos que produziram quatro diferentes tipos de produção tecnológica. Porém, em relação à quantidade, os pesquisadores desse departamento estão com baixa produtividade tecnológica (quando comparados a pesquisadores do Departamento de Agronomia), somando oito produções, o total de produções tecnológicas identificadas nesta pesquisa foi de 65 .

Os pesquisadores dos Departamentos de Zootecnia e Ciência e Tecnologia de Alimentos abordaram as temáticas: valor nutritivo de alimento; tecnologia de produtos de origem vegetal; química; física; físico-química e bioquímica de alimentos e das matérias-primas alimentares; avaliação e controle de qualidade de alimentos; e embalagens de produtos alimentares.

\footnotetext{
${ }^{2}$ Professores/pesquisadores.
} 
As produções tecnológicas encontradas tiveram como principal temática a avaliação e controle de qualidade de alimentos e embalagens de produtos alimentares, formando parcerias, por meio de coautorias, entre os Departamentos de Agronomia, Zootecnia, Ciência e Tecnologia de Alimentos.

A titulação dos professores não influenciou na importância ou na forma da produção tecnológica, não havendo diferença entre a produção do livre docente, dos pós-doutores e dos doutores. Um fator que pode ter contribuído para isso são as coautorias, pois com a produção em conjunto há o compartilhamento de experiências e informações, acarretando benefícios para ambas as partes.

Todas as produções estão em sintonia com a área de especialidade dos professores, inclusive as em coautoria; $51 \%$ dos professores apresentaram pelo menos uma produção tecnológica em sua produção cadastrada no currículo Lattes, nos itens Produção Bibliográfica, Produção Técnica, ou nos Demais Trabalhos.

A área de Ciências Agrárias da UEL possui um estímulo maior para a produção bibliográfica, visto que todos a possuem, e que em vários casos a produção bibliográfica dissemina uma produção tecnológica.

Fujino, Stal e Plonski (1999) mencionam que a questão da pesquisa acadêmica deve ser caracterizada pela liberdade de investigação, e pela obrigatoriedade de incentivar o livre fluxo das informações por meio de publicações, e outros meios de divulgação dos conhecimentos gerados para a sociedade. Logo, os professores da área de Ciências Agrárias da UEL com esse alto índice em produção bibliográfica condicionam o livre fluxo das informações por meio das publicações para que seja disseminado a todos.

Independente da coautoria, a produção de cada professor foi considerada individualmente, situação que potencializa o aumento da produção tecnológica identificada. Outro fator que influenciou na quantidade da produção é o fato de publicarem a mesma produção em diferentes línguas, ou quando o professor desenvolve uma produção tecnológica a dissemina em publicações e também a cadastra como produção técnica.

Gráfico 1 - Total da produção tecnológica da área de Ciências Agrárias

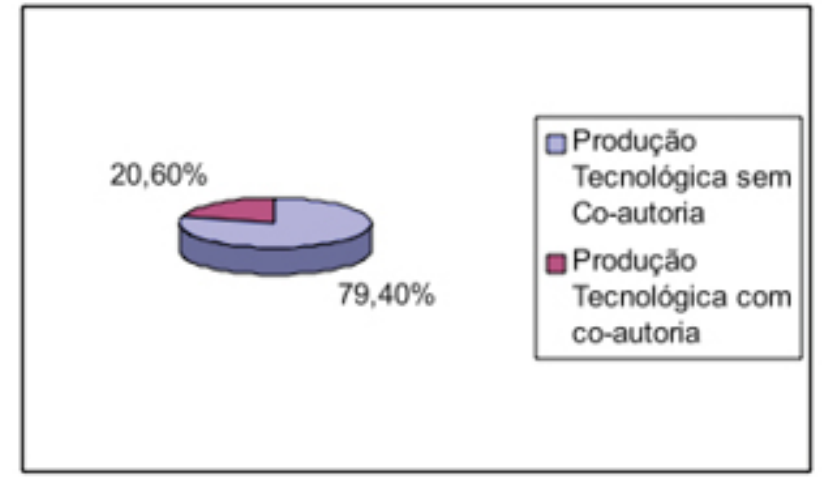

Fonte: os autores.

Logo essa produção pode ser cadastrada mais de uma vez nos itens de: Produção Bibliográfica, Produção Técnica e Demais trabalhos do currículo Lattes, o que também potencializou o aumento da produção. Esse impacto quantitativo ilusório na produção só foi percebido no final da análise dos dados levantados.

O total de 65 itens de produção tecnológica identificados nesta pesquisa teve um aumento de $20,6 \%$, que equivale a 14 produções tecnológicas, devido às coautorias entre os professores contemplados com a bolsa de iniciação cientifica (Gráfico 1).

Figura 2 - Mapeamento por produção tecnológica

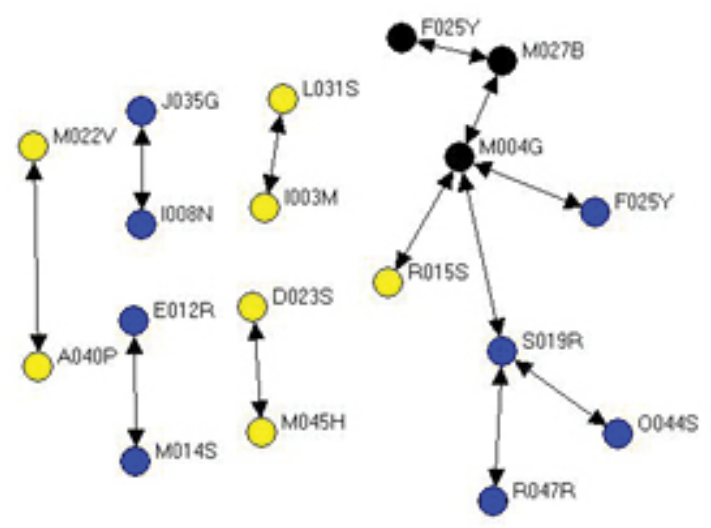

Fonte: os autores. 
As produções em coautorias atingiram 20\% do total de coautores, a temática centrou-se, principalmente, na especialidade embalagens para alimentos. Os Departamentos de Agronomia, Ciência e Tecnologia de Alimentos e o de Zootecnia estão no grupo que corresponde aos $20 \%$ do total de coautorias na temática de embalagens para alimentos, identificadas na Figura 2 pelas ligações do pesquisador M004G.

Aproximadamente Setenta e nove por cento $(79,4 \%)$ da produção tecnológica encontrada não foi desenvolvida em parceria, percentual que totalizou 51 produções tecnológicas. Em alguns casos, as publicações foram compiladas com outros autores (não participantes desta pesquisa).

A Figura 2 possibilita a visualização por coautorias dos atores e por tipo de produção. Os círculos com a cor amarela se referem às produções tecnológicas classificadas como processos tecnológicos. A cor azul se refere aos produtos tecnológicos que foram produzidos aos pares, bem como em grupos de três professores, com destaque para o ator S019R que liga três pesquisadores. E os pontos com a cor preta se referem aos pesquisadores que têm produção tecnológica de produtos e também processos tecnológicos, o maior número de ligações mantidas foi pelo ator M004G, com quatro ligações.

\section{Produção Bibliográfica, Técnica e Demais Trabalhos}

A análise, aqui apresentada, envolve (no geral) os três tipos de produção: a bibliográfica, a técnica e os demais trabalhos. A análise específica, demonstrada a seguir, evidencia as produções, cada tipo com sua singularidade.

O Departamento de Agronomia apresenta maior número de publicações bibliográficas, que disseminam produções tecnológicas, e produção técnica, obtendo $43 \%$ do total dessas produções mencionadas, e o de Medicina Veterinária Preventiva apresenta maior variedade nas produções.
Os Departamentos de Ciência e Tecnologia de Alimentos e Zootecnia mostram um bom nível de produção bibliográfica em relação ao Departamento de Agronomia que é o que possui o maior índice (39\%), visto que os dois departamentos citados possuem menor número de professores e apresentam respectivamente $27 \%$ e $23 \%$ da quantidade total de publicação bibliográfica.

O Departamento de Clínicas Veterinárias possui poucos professores contemplados com bolsa do PROIC, o que justifica o baixo percentual de $1,4 \%$ da produção bibliográfica com produto tecnológico.

A produção técnica é liderada pelo Departamento de Agronomia com $56 \%$ da produção técnica. O Departamento de Agronomia demonstra, pelos altos percentuais em suas produções bibliográficas e técnicas, o interesse pela busca, descoberta, experimentações, dessa forma ocorre o desenvolvimento e adoção de novos produtos, novos softwares, e novos processos.

\section{a) Produção bibliográfica}

A Tabela 1 apresenta as publicações bibliográficas que disseminam produções tecnológicas. A análise desta tabela evidencia que:

a) o Departamento de Agronomia tem a maior quantidade de publicações em coautoria, em relação aos outros Departamentos,

- $40 \%$ do total das publicações são em coautorias;

- 46\% são publicações de autores vinculados apenas da UEL - autorias institucionais;

- 51\% estão publicadas em língua nacional;

- 65\% das publicações estão disponíveis em suporte on-line;

- metade da produção encontrada está indexada no ISI Web of Science.

b) os Departamentos de Zootecnia detêm $23 \%$ da produção bibliográfica total, e 
Tabela 1 - Produção Bibliográfica

\begin{tabular}{|c|c|c|c|c|c|c|c|c|c|c|c|c|}
\hline \multirow[t]{2}{*}{ Departamento } & \multicolumn{12}{|c|}{ Produção bibliográfica } \\
\hline & Total & Ind. & Coaut. & Inst. & Interinst. & $\begin{array}{l}\text { Pub. em } \\
\text { Port. }\end{array}$ & $\begin{array}{l}\text { Pub. em } \\
\text { Inglês }\end{array}$ & Impresso & $\begin{array}{l}\text { Eletr. } \\
\text { On-line }\end{array}$ & $\begin{array}{l}\text { CD- } \\
\text { ROM }\end{array}$ & Qualis & $|S|$ \\
\hline Agronomia & 17 & 01 & 16 & 15 & 02 & 20 & 06 & 07 & 13 & 00 & 13 & 05 \\
\hline $\begin{array}{l}\text { Clínicas } \\
\text { Veterinárias }\end{array}$ & 01 & 00 & 01 & 01 & 00 & 01 & 00 & 01 & 01 & 00 & 01 & 00 \\
\hline $\begin{array}{l}\text { Medicina } \\
\text { Veterinária } \\
\text { Preventiva }\end{array}$ & 04 & 03 & 01 & 03 & 01 & 02 & 02 & 01 & 02 & 01 & 02 & 02 \\
\hline $\begin{array}{l}\text { Ciência e } \\
\text { Tecnologia de } \\
\text { Alimentos }\end{array}$ & 12 & 00 & 12 & 08 & 04 & 09 & 04 & 06 & 12 & 00 & 12 & 02 \\
\hline Zootecnia & 10 & 00 & 10 & 06 & 04 & 07 & 06 & 02 & 09 & 00 & 04 & 02 \\
\hline
\end{tabular}

Fonte: os autores.

o de Ciência e Tecnologia de Alimentos $27 \%$;

c) o Departamento de Ciência e Tecnologia de Alimentos participa em 36\% das produções bibliográficas de autoria institucional e, $72 \%$ de produção bibliográfica de autoria Interinstitucional, e o Departamento de Zootecnia detêm 30\% de produção bibliográfica de autoria institucional e $36 \%$ produção bibliográfica de autoria interinstitucional;

d) há a prevalência de publicação em periódicos eletrônicos com a média de $28 \%$ do total das produções bibliográficas;

e) no Departamento de Medicina Veterinária Preventiva constatouse que $9 \%$ da produção bibliográfica dissemina uma produção tecnológica, porém, apresenta $50 \%$ dessa produção no Sistema Qualis ${ }^{3}$ da Coordenação de Aperfeiçoamento de Pessoal de Nível Superior (CAPES) e indexada no ISI Web Of Science. Este Departamento demonstra que produz tanto em veículos impressos (25\%), como em eletrônicos on-line (50\%) e off-line (CD-ROM) $25 \%$ da sua produção bibliográfica;

f) o Departamento de Clínicas Veterinárias publicou somente em língua nacional, em periódico de caráter impresso e eletrônico, certificado pelo sistema Qualis.

A modalidade de publicação eletrônica tem se tornado um meio de disseminação importante, e gerou o aumento da quantidade de publicação, por possibilitar diversas vantagens e facilidades (CAFÉ et al., 2002).

O fato de haver autorias interinstitucionais indica que as parcerias podem possibilitar a troca e compartilhamento de conhecimento e equipamentos, auxiliando o desenvolvimento das produções. A interação entre a Universidade e outros órgãos externos garante vantagens de desenvolvimento e caracteriza o espaço ou ambiente de produção tecnológica.

Conforme discorrido por Santos (1992), sobre o espaço de produção tecnológica ser uma estrutura demográfica, com uma produção, com estruturação de arranjos e modelos produtivos que garantam o suporte adequado para o desenvolvimento da produção tecnológica. Com isso, nota-se que as autorias interinstitucionais são responsáveis pela estruturação do espaço tecnológico, pois por meio dessas publicações há a oportunidade de ampliar os recursos, o que possibilita desenvolver as produções tecnológicas com maior qualidade.

\footnotetext{
${ }^{3}$ http://qualis.capes.gov.br/webqualis/.
} 
Tabela 2 - Produção Técnica dos professores contemplados com bolsa do PROIC

\begin{tabular}{|l|c|c|c|c|c|}
\hline \multirow{2}{*}{ Departamento } & \multicolumn{5}{|c|}{ Produção bibliográfica } \\
\cline { 2 - 6 } & Total & Individual & Co-autoria & Institucional & Interinstitucional \\
\hline Agronomia & 13 & 02 & 11 & 13 & 00 \\
Clinicas Veterinárias & 00 & 00 & 00 & 00 & 00 \\
Medicina Veterinária Preventiva & 07 & 01 & 06 & 07 & 00 \\
Ciência e Tecnologia de Alimentos & 02 & 01 & 01 & 02 & 00 \\
Zootecnia & 02 & 00 & 02 & 02 & 00 \\
\hline
\end{tabular}

Fonte: os autores.

\section{b) Produção técnica}

Pela análise da Tabela 2, que aborda a produção técnica dos professores contemplados com bolsa do PROIC, pode-se perceber que:

a) o Departamento de Agronomia possui $55 \%$ do total das produções técnicas, $84 \%$ são em coautoria;

b) o Departamento de Medicina Veterinária Preventiva detém $29 \%$ das produções técnicas, há também a prevalência de $85 \%$ de coautoria;

c) o Departamento de Ciência e Tecnologia de Alimentos atinge $8 \%$ do total das produções técnicas, $50 \%$ de autoria individual e $50 \%$ em coautoria;

d) o Departamento de Zootecnia também possui $8 \%$ do total das produções técnicas, com $100 \%$ em coautoria e,

e) o Departamento de Clínicas Veterinárias não tem produção classificada como produção tecnológica;

f) $100 \%$ da produção são de autores vinculados a uma mesma instituição - a UEL.

$\mathrm{Na}$ Tabela 2 observa-se a prevalência da produção em coautoria. Além disso, nem todas as produções técnicas encontradas se configuram como produção tecnológica, como por exemplo: as palestras e as consultorias não apresentam características tecnológicas.

Identificou-se, também, que a Instituição, pelo menos, no que se refere à Produção Técnica, não faz parcerias com outras instituições, o que deixa a UEL como a única detentora da produção identificada. Percebeu-se que é possível produzir individualmente, ou em conjunto dentro da própria Universidade, mostrando certa autossuficiência.

\section{Quadro 3 - Descrição de Manuais}

\begin{tabular}{|c|c|}
\hline $\begin{array}{l}\text { Manual por } \\
\text { Departamento }\end{array}$ & Finalidades/ Características \\
\hline $\begin{array}{l}\text { Medicina } \\
\text { Veterinária } \\
\text { Preventiva }\end{array}$ & $\begin{array}{l}\text { Manual Educativo sobre Zoonoses, Manual } \\
\text { Técnico de Leishmaniose Tegumentar Canina } \\
\text { produzido por I008N - (Especialidade: } \\
\text { Zoonoses e Saúde Pública). }\end{array}$ \\
\hline $\begin{array}{l}\text { Medicina } \\
\text { Veterinária } \\
\text { Preventiva }\end{array}$ & $\begin{array}{l}\text { Manual com o Programa de controle as } \\
\text { Zoonoses também produzido por } 1008 \mathrm{~N} \\
\text { dentro de sua especialidade. }\end{array}$ \\
\hline $\begin{array}{l}\text { Manual por } \\
\text { Departamento }\end{array}$ & Finalidades/ Caracteristicas. \\
\hline $\begin{array}{l}\text { Medicina } \\
\text { Veterinária } \\
\text { Preventiva }\end{array}$ & $\begin{array}{l}\text { Manual para vigilância de Epizootias em } \\
\text { Primatas Não Humanos do Estado do Paraná } \\
\text { (SESA-PR) também produzido por I008N. }\end{array}$ \\
\hline $\begin{array}{l}\text { Medicina } \\
\text { Veterinária } \\
\text { Preventiva }\end{array}$ & $\begin{array}{l}\text { Manual em CD-ROM que contém o } \\
\text { treinamento em métodos de diagnóstico e } \\
\text { controle da brucelose e tuberculose e noções } \\
\text { em EET. Elaborado por E033M inserido } \\
\text { na sua Subárea de Medicina Veterinária } \\
\text { Preventiva. }\end{array}$ \\
\hline $\begin{array}{l}\text { Medicina } \\
\text { Veterinária } \\
\text { Preventiva }\end{array}$ & $\begin{array}{l}\text { Manual que consta o programa nacional } \\
\text { de controle e Erradiação da brucelose e } \\
\text { tuberculose animal, se caracterizando } \\
\text { manual técnico, também elaborado por } \\
\text { E033M dentro da sua perspectiva. }\end{array}$ \\
\hline $\begin{array}{l}\text { Ciência e } \\
\text { Tecnologia de } \\
\text { Alimentos }\end{array}$ & $\begin{array}{l}\text { Manual desenvolvido com finalidade didática } \\
\text { ou instrucional (apostila). Contendo o } \\
\text { Perfil Livre e avanços em análise sensorial } \\
\text { descritiva. Elaborado por M027B (Ciência } \\
\text { e Tecnologia de Alimentos) dentro de sua } \\
\text { especialidade em Avaliação e Controle de } \\
\text { Qualidade de Alimentos; Química, Física, } \\
\text { físico-químico e Bioquímica dos Alimentos. e } \\
\text { das Matérias-Primas Alimentares. }\end{array}$ \\
\hline
\end{tabular}

Fonte: os autores. 
c) Demais trabalhos

No sub-tópico "Demais trabalhos" do currículo Lattes, o único Departamento que apresenta produção tecnológica é o de Medicina Veterinária Preventiva, com o índice de $67 \%$ de coautorias e $33 \%$ de autoria individual.

Foi identificado no Departamento de Medicina Veterinária Preventiva o percentual de 67\% de autoria institucional e $33 \%$ de autoria interinstitucional do total de três produções tecnológicas encontradas nesse Departamento.

$\mathrm{Na}$ produção tecnológica identificada como manual (Quadro 3), há a prevalência de $83 \%$ da produção total pelo Departamento de Medicina Veterinária Preventiva, desenvolvida por dois doutores na especialidade de "zoonoses e saúde pública”.

Percebe-se pelo Quadro 3 que, além do Departamento de Medicina Veterinária, o Departamento de Ciência e Tecnologia de Alimentos também produziu manuais em temas diversificados. Os outros professores, contemplados com a bolsa de iniciação científica, vinculados aos demais departamentos não produziram manuais.

Os processos foram encontrados em maior número, em relação às demais tipologias de produção tecnológicas relatadas neste estudo, o que indica a preferência no desenvolvimento de processos. Todos os Departamentos produziram pelo menos um processo. Os processos desenvolvidos, segundo suas características, auxiliam no bom rendimento da agricultura, diminuindo os danos, gastos, epidemias, tempo do agricultor, e agilizando o processo de desempenho das atividades a serem executadas.

E ainda, os processos apresentam soluções que podem resultar em benefícios para o desenvolvimento econômico da sociedade. Encontramos 23 processos com maior ênfase na área de alimentos, especificamente no melhoramento da qualidade.
Alguns dos produtos originaram-se dos processos encontrados, como por exemplo, o método isolado para controle da broca do café, que gerou um protocolo (produto tecnológico) para teste in vitro. Outro exemplo é o processo para obtenção de fécula de inhame, que acarretou na criação do produto "filme biodegradável". Constatouse então que a partir do conhecimento prévio, ressaltado por Machado (2006) como parte do conhecimento acumulado, os professores investigados desenvolveram produtos tecnológicos.

$\mathrm{Na}$ tipologia categorizada como produto, identificou-se 25 itens com propósitos diversos, desde a fabricação de bandejas para alimentos, ou adaptações em produtos agrícolas, à criação de vacinas e micro-organismos. A contribuição dos produtos está relacionada a três finalidades distintas: a) aprimoramento, e/ou avanço da área de Ciências Agrárias; b) geração de desenvolvimento econômico e social; c) auxiliar a Universidade a cumprir parte de sua missão, que é produzir conhecimento para o desenvolvimento social.

Os softwares foram criados, em maior quantidade, pelo Departamento de Agronomia, seguido pelo Departamento de Zootecnia, e pelo Departamento de Ciência e Tecnologia de Alimentos.

Os softwares identificados (nove) têm como propósito auxiliar nos cálculos, na avaliação de riscos climáticos, simulações para aprendizado, e detecção de contaminação de alimentos.

Esses softwares respaldam a tomada de decisão do profissional que o utilizará, proporcionando a diminuição da margem de erro. Não foi encontrado nenhum software com registro no Instituto Nacional de Propriedade Industrial (INPI), sistema de propriedade industrial que garante por meio de leis e direitos, restrições e explicações em termos de proteção ao software (FRANÇA, 1997).

O INPI concede o registro de direito autoral para a modalidade "softwares" e neste estudo não foi identificado nenhum software que esteja 
protegido pela legislação vigente de direito autoral.

Alguns dos softwares encontrados estão disseminados na Web para comercialização e podem ser recuperados pelo sistema de busca do mecanismo de busca Google.

\section{Canais de comunicação}

A comunidade científica, com destaque neste estudo para os Departamentos de Agronomia e Zootecnia, usa amplamente os canais de informação, disseminando em grande escala suas publicações e divulgando suas pesquisas em periódicos variados, fatores que contribuem para que a informação alcance um número maior de pessoas.

Somente quatro dos periódicos que disseminam suas produções não são certificados pelo Sistema Qualis e metade das publicações está indexada no ISI web of Science. Também vale ressaltar que publicam em periódicos de acesso aberto (Open Arquives Initiative - OAI) e restrito, sendo que a publicação neste último segmento dificultou um melhor detalhamento da produção tecnológica. Apenas 28\% dos periódicos identificados são adeptos da filosofia de OAI. Isto indica que parte das pesquisas está sendo disseminada por acesso livre e fica evidenciado o interesse dos pesquisadores em divulgar os resultados ampla e irrestritamente.

Outro ponto evidente é a publicação endógena na revista "Semina" da Universidade Estadual de Londrina, que possui $32 \%$ do número de publicações.

\section{Considerações finais}

A produção tecnológica da área de Ciências Agrárias da UEL alcançou o total de 65 itens, sendo a maior parte disseminada por meio da produção bibliográfica.

Percebeu-se que além da atividade de pesquisa básica, na área de Ciências Agrárias, há também a atividade de pesquisa aplicada junto com a experimentação e com potencial para lançamento no mercado. Situação esta que pode acarretar em novos produtos, novos softwares, novos manuais e novos processos, como os identificados neste estudo.

O mapeamento das formas de produção tecnológica, além de ter proporcionado a identificação dos produtos, processos tecnológicos, softwares e manuais na área pesquisada, possibilitou a visualização dos trabalhos em parcerias. Os pesquisadores participantes deste estudo fazem parcerias em um mesmo Departamento, ou em Departamentos variados, dentro e fora da Universidade, interagindo e compartilhando as experiências, o conhecimento e os equipamentos, o que potencializa uma produção tecnológica mais bem formulada e com maiores chances de êxito.

Os canais de comunicação mais utilizados foram os periódicos, só havendo um livro e um capítulo de livro em que a produção foi divulgada.

Um percentual considerável de artigos foi publicado em periódicos adeptos da filosofia da Open Archives Initiative (OAI), o que possibilita o acesso livre e alta disseminação dos resultados das pesquisas.

A produção dos pesquisadores demonstra que estão contribuindo para que a universidade atinja um de seus objetivos - contribuir no atendimento das necessidades da sociedade.

A interação entre os atores na universidade indica que a pesquisa acadêmica e a pesquisa que resulta em inovação tecnológica, além de fomentar o capital intelectual, auxiliam no bom desenvolvimento de atividades nas quais o compartilhamento de recursos e conhecimento é o principal ativo da produção tecnológica. 


\section{Referências}

BERNARDES, R. Produção de estatísticas e inovação tecnológica PAEP 1996-2001. São Paulo em

Perspectiva, São Paulo, v. 17, p. 3-4, 2003.

CAFÉ, L. et al. Arquivos abertos: inovação tecnológica para comunicação científica na rede. In: CONGRESSO BRASILEIRO DE CIÊNCIAS DA COMUNICAÇÃO, 25., 2002, Salvador. Comunicação para cidadania. Anais... Salvador: Sociedade Brasileira de Estudos Interdiciplinares da Comunicação, 2002.

CALDAS, R. de A. et al. Gestão estratégica em ciência, tecnologia e inovação. Parcerias Estratégicas, Brasília, DF, v. 11, p. 48-73, 2001. Disponível em: <http://www. cgee.org.br/parcerias/p11.php $>$. Acesso em: 10 maio 2007.

CONCEIÇÃO, C. P. Protagonistas e contextos da produção tecnológica em Portugal: o caso da invenção independente. Sociologia: problemas e práticas, n. 41, p. 119-138, 2003.

FAVA-DE-MORAES, F. Universidade, inovação e impacto socioeconômico. São Paulo em Perspectiva, São Paulo, v. 14, n. 3, 2000. Disponível em: <http://www. scielo.br/scielo.php?script=sci_arttext\&pid=S0102$88392000000300003 \& \operatorname{lng}=\mathrm{pt} \& \mathrm{nrm}=\mathrm{iso}>$. Acesso em: 10 maio 2007.

FRANÇA, R. O. Patente como fonte de informação tecnológica. Perspectivas em Ciência da Informação, Belo Horizonte, v. 2, n. 2, p. 235-264, jul./dez. 1997. Disponível em: <http://portaldeperiodicos.eci.ufmg. br/index.php/pci/article/viewFile/636/425>. Acesso em: 18 abr. 2007.

FUJINO, A.; STAL, E.; PLONSKI, G. A. A proteção do conhecimento na universidade. Revista de Administração, São Paulo, v. 34, n. 4, out./dez. 1999. Disponível em: <http://www.rausp.usp.br/download. asp?file=3404046.pdf $>$. Acesso em: 13 jun. 2007.

GOLDEMBERG, J. Tecnologia apropriada: encontros com a civilização brasileira. Rio de Janeiro, n. 3, 1978.

LEMOS, C. Inovação na era do conhecimento. In: LASTRES, H. M. M.; ALBAGLI, S. (Org.). Informação e globalização na era do conhecimento. Rio de Janeiro: Campus, 1999. Cap. 5, p. 122-144.

MACHADO, C. J. S. As relações entre tecnologia, inovação e sociedade. Datagramazero: revista de Ciência da Informação, Rio de Janeiro, v. 7, n. 1, fev. 2006. Disponível em: <http://www.dgz.org.br/fev06/ F_I_art.htm>. Acesso em: 19 abr. 2007.
SANTOS, M. Espaço e método. 3. ed. São Paulo: Nobel, 1992. $88 \mathrm{p}$.

SCHUMPETER, J. Ensaios: empresários, inovação, ciclos de negócio e evolução do capitalismo. Oeiras: Celta, 1996.

Study of the technological production at the State University of Londrina (UEL): mapping the area of Agricultural Sciences by Platform Lattes

\section{Abstract}

Introduction: Technological products and processes employed to solve society's practical problems comprise technological production, which is the essential means to measure the technological development of the environment in which the institution is inserted. This research aimed to verify the State University of Londrina's (UEL) technological production in the field of Agro-Sciences. Method: The methodological approach was to identify and analyze technological production through the curricula of the 51 professors granted with scholarships by UEL's Scientific Initiation Program (PROIC) available at the Lattes Platform. The data collected for analysis was charted and categorized according to technological production typology. Results: Of the 65 registered items in the researchers'curricula lattes refer to the technological production. Those items were mapped in order to describe the types identified. It was observed that the most innovative specialties are Agronomy, Forestry and Forest Engineering, Agricultural Engineering, Animal Science, Veterinary Medicine, Fisheries Resources and Fishing Engineering, Science and Food Technology. Conclusions: The production resulting from research activities of technological development, has spread through the production literature, primarily journal articles. Researchers build partnerships in the same Department, or with others within and outside the University, interacting and sharing experiences, knowledge and equipment. This practice improves a technological production that is more likely to be successful. A considerable percentage of articles are published in Open Archives Initiative(OAl) journals, allowing free access and encourages the dissemination of research results.

\section{Keywords}

Technological Production; Technological Development; Technological innovation. 
Recebido em 27 de fevereiro de 2011

Aceito em 19 de março de 2011

${ }^{1}$ Graduado em Biblioteconomia - UEL, Pós-Graduando em Gestão Pública - Universidade de Mogi das Cruzes/ SP. Especialista em Informações Técnicas, Culturais e Desportivas - Secretaria Municipal de Cultura / Biblioteca Mário de Andrade (São Paulo).

nserzedello@prefeitura.sp.gov.br

${ }^{2}$ Graduada em Biblioteconomia, Doutora em Ciência da Informação - UFMG. Professora - Universidade Estadual de Londrina/Departamento de Ciência da Informação.

mitomael@uel.br

Como citar este artigo:

SERZEDELLO, N. T. B.; TOMAÉL, M. I. Produção tecnológica da Universidade Estadual de Londrina (UEL): mapeamento da área de Ciências Agrárias pela Plataforma Lattes. AtoZ, Curitiba, v. 1, n. 1, p. 23-37, jan./jun. 2011. Disponivel em: <http://www.atoz.ufpr.br>. Acesso em: 